\title{
Reduction of Peroxide Number in Crude Palm Oil (CPO) Using Rubber Fruit Shell (Heveabra silliensis) as Bio-sorbent
}

\section{SETIATY PANDIA*, MERSI SURIANI SINAGA, AMIR HUSIN, SITI NURFADILLA SIREGAR, HIMSAR AMBARITA and FITRIANI INDAH LESTARI}

\author{
Department of Chemical Engineering, Faculty of Engineering, Universitas Sumatera Utara, \\ Padang Bulan, Medan 20155, Indonesia. \\ ${ }^{\star}$ Corresponding author E-mail: setiaty_pandia@yahoo.com
}

http://dx.doi.org/10.13005/ojc/340149

(Received: November 09, 2017; Accepted: December 20, 2017)

\begin{abstract}
The object of this study was to discover the effectiveness of the shell of rubber fruit as bio sorbent for removing peroxide number in (CPO) Crude Palm Oil and heavy metals (Cu, Ni) contained in Metal Coating Industry's wastewater. Methods used were pretreatment, activation (carbonating and chemically) and adsorption process at room temperature. In the beginning, the shell of rubber fruit was cleaned and dried under the sun. Then the shell was cut for about $0.5 \mathrm{~cm}$ of length and carbonated in a furnace for $1 \mathrm{~h}$ at $500^{\circ} \mathrm{C}, 550^{\circ} \mathrm{C}, 600^{\circ} \mathrm{C}$, and $650^{\circ} \mathrm{C}$. After that, they were crushed to pass through 140 meshes and activated using $6 \mathrm{~N}$ of $\mathrm{HNO}_{3}, 6 \mathrm{~N}^{\circ} \mathrm{H}_{3} \mathrm{PO}_{4}$ and $6 \mathrm{~N}$ of $\mathrm{KOH}$ at certain ratio as $1: 3,1: 4$, and $1: 5(\mathrm{~m} / \mathrm{v})$. The adsorption process was carried out using bio sorbent with the highest iodine number in varyingbio-sorbent dosage and contact time. The high stiodine number was $913.680 \mathrm{mg} / \mathrm{g}$ and obtained at the ratio of bio sorbent to $6 \mathrm{~N}$ of $\mathrm{KOH}$ as 1:5. The best reduction of peroxide number was $83.86 \%$ at $0.5 \%$ bio-sorbent dose and 40 min of contact time.
\end{abstract}

Keyword: Activation, Adsorption, CPO (Crude Palm Oil), Peroxide number.

\section{INTRODUCTION}

Rubber plantation is one of a plantation which is well developing in agriculture in Indonesia. Physically the shell of rubber fruit (Heveabra siliensis) is known as a plant with lignin contained. According are Zakaria et al., (2015) $)^{1}$, the shell of rubber fruit contains active compound which is lignin. The use of the shell of rubber fruit is not optimal yet although its content of lignin is relatively $(35 \%-54 \%)^{1}$ Therefore it is potential to become an activated carbon product, namely bio sorbent.Several studies

This is an Open Access article licensed under a Creative Commons Attribution-NonCommercial-ShareAlike 4.0 International License (https://creativecommons.org/licenses/by-nc-sa/4.0/), which permits unrestricted NonCommercial use, distribution and reproduction in any medium, provided the original work is properly cited. 
have been conduct that used part of a rubber tree, such as the powder of rubber wood sewed to diminish chromium (VI) content in a solution and the leaf of rubber plant to minimize cuprum ion using sodium hydroxide in solution ${ }^{1}$.

The initial stage of (CPO) Crude Palm Oil raffination is the removal of gum (degumming) followedby bleaching, deodorization and fractionation ${ }^{2}$. Conventionally, degumming is the flock's formation of substance that is colloidal. Peroxide number is meq peroxide in $1000 \mathrm{~g}$ of oil or fat which is an important value to ensure the damage of oil or fat. It is due to oxydation and hydrolitical process, especially because of autoxydation which can affect the taste of fat or oil. Furthermore it can be resulted in rancid due to aldehyde and ketone. The degree of damage at fat or oil can be expressed as peroxide number ${ }^{3}$.

\section{MATERIAL AND METHOD}

\section{Material}

The main materials were the shell of rubber fruit and crude palm oil that were obtain from the neighborhood around the University of Sumatera Utara. Potassium hydroxide, phosphate acid, and nitric acid were use in bio-sorbent activation. Acetic acid, chloroform, $\mathrm{KI}, \mathrm{Na}_{2} \mathrm{~S}_{2} \mathrm{O}_{3}$ were used for analysis purpose.

\section{Bio-sorbent Activation}

The shell of rubber fruit was washed with water and dried in the sunlight. They were cutting in $0.5 \mathrm{~cm}$ long in average and then they were carbonated in a furnace for $1 \mathrm{~h}$ at $500{ }^{\circ} \mathrm{C}, 550^{\circ} \mathrm{C}$ $600{ }^{\circ} \mathrm{C}$ and $650^{\circ} \mathrm{C}$. After that, they were crushed to powder form and passed through 140 meshes. Bio sorbent was activateing with a solution of $6 \mathrm{~N} \mathrm{H}_{3} \mathrm{PO}_{4}$. Other solutions for activating use were $6 \mathrm{~N} \mathrm{KOH}$ and $6 \mathrm{~N} \mathrm{HNO}_{3}$. It was follow by washing several times with distilled water to remove the activating solution. The procedure was repeate for the ratio of bio-sorbent:solution of 1:3, 1:4 and 1:5 (m/v).

\section{Analysis of lodine Number}

lodine number shows the unsaturated fatty acid composed of oil and fat. The unsaturated fatty acid can bind iodine and make a saturated compound. lodine number is stated as the number of iodin compound which is bound by 100 grams of oil or fat.

\section{RESULTS AND DISCUSSION}

\section{Effect of Type of Activating Solution and Ratio of Bio-sorbent to Solution to lodine Number}

Before and after activation, an iodine number of the bio sorbent was analyzed. The iodine number before activation was $545.799 \mathrm{mg} / \mathrm{g}$, while the iodine numbers after activation were given in Figure 1 to Figure 4 below

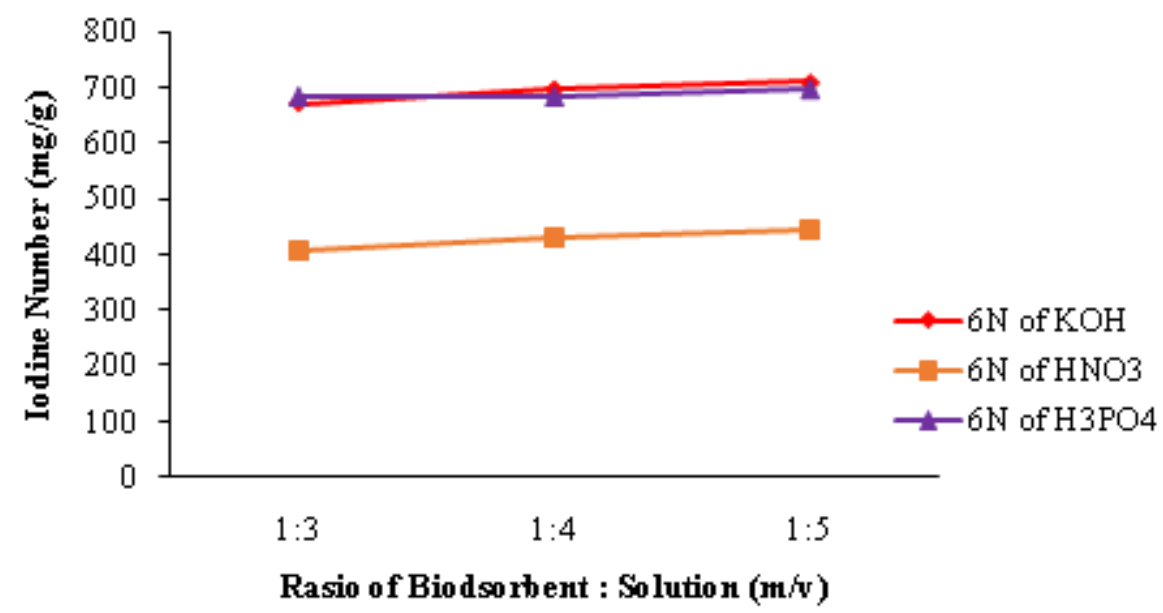

Fig. 1. lodine Number of Bio-Sorbent at $500{ }^{\circ} \mathrm{C}$ 


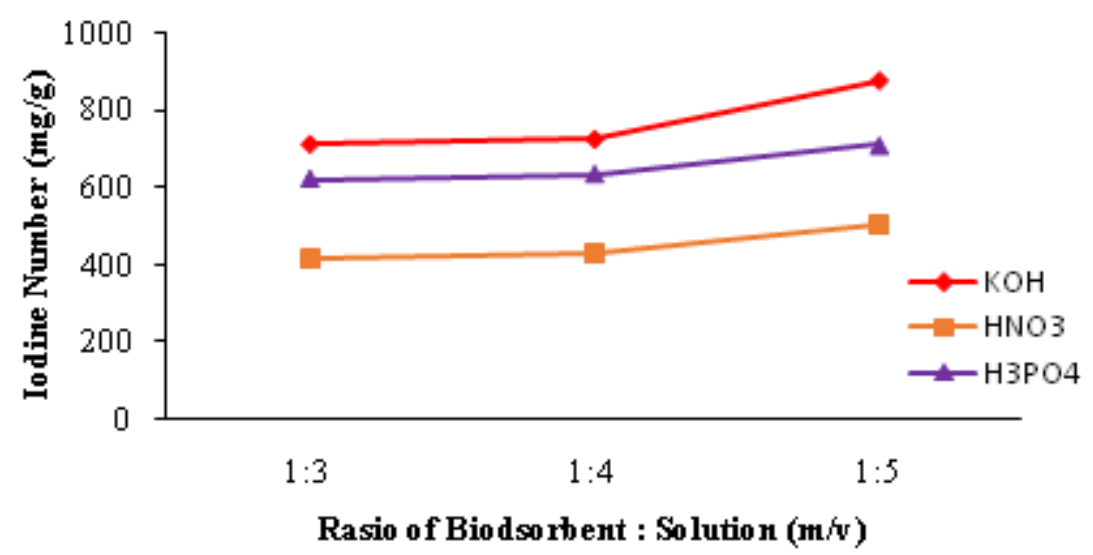

Fig. 2. lodine Number of Bio Sorbent at $550{ }^{\circ} \mathrm{C}$

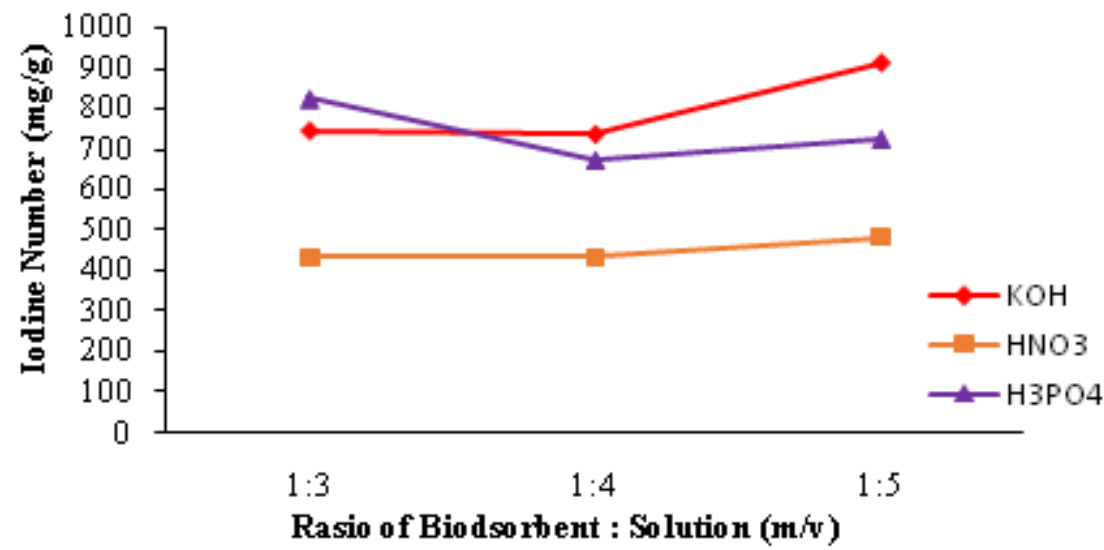

Fig. 3. lodine Number of Bio Sorbent at $600^{\circ} \mathrm{C}$

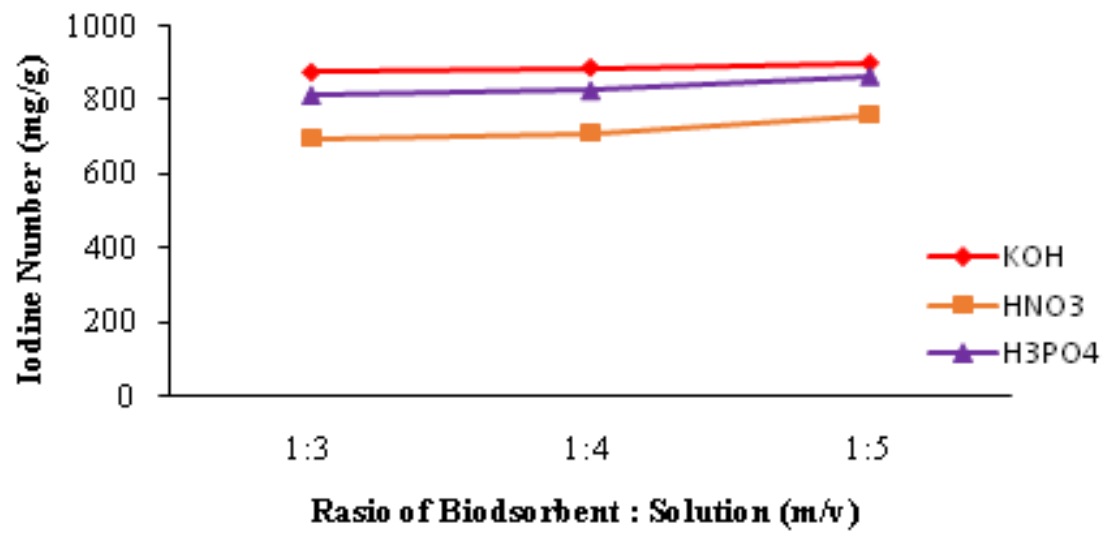

Fig. 4. lodine Number of Bio Sorbent at $650^{\circ} \mathrm{C}$ 
From Fig. 1 to Fig. 4, the irregularity occurred. It is maybe due to a water content of the after-water bio-sorbentcannot be controlled. In general, it is shown that $\mathrm{KOH}$ as activating solution is more effective compared with $\mathrm{H}_{3} \mathrm{PO}_{4}$ and $\mathrm{HNO}_{3}$. $\mathrm{KOH}$ is a strong base solution, therefore it is more affecting the active pore information.Furthermore the increase of the ratio of bio sorbent to activating solution fond increases the iodine number. A very low concentration of activator may cause the in complete formation of the active sites where as a very high ratio of activator may cause damage to the structure of the bio-sorbent ${ }^{4}$. By comparing theory and result obtained from the research, it can be concluded that the most favorable conditions to produce the bio-sorbent from the shell of rubber fruit with the highest iodine number are the ratio of bio sorbent, potassium hydroxide of the $1: 5$ at $600{ }^{\circ} \mathrm{C}$.

According to $\mathrm{SN}^{1}-06-3730-1995$, the resulting bio sorbent is already qualified as activated carbon. It is seen from iodine number $913.68 \mathrm{mg} / \mathrm{g}$, vapor content $2.64 \%$, ash content $9.88 \%$ and water content $14.77 \%$. Where the requirements given by SNI in the table below

Table. 1: Standardof Activated Carbon from $\mathrm{SN}^{1}$

\begin{tabular}{lc}
\hline Requirements & Content \\
\hline lodine Number & $>750 \mathrm{mg} / \mathrm{g}$ \\
Vapor Content & $<25 \%$ \\
Ash Content & $<10 \%$ \\
Water Content & $<15 \%$ \\
\hline
\end{tabular}

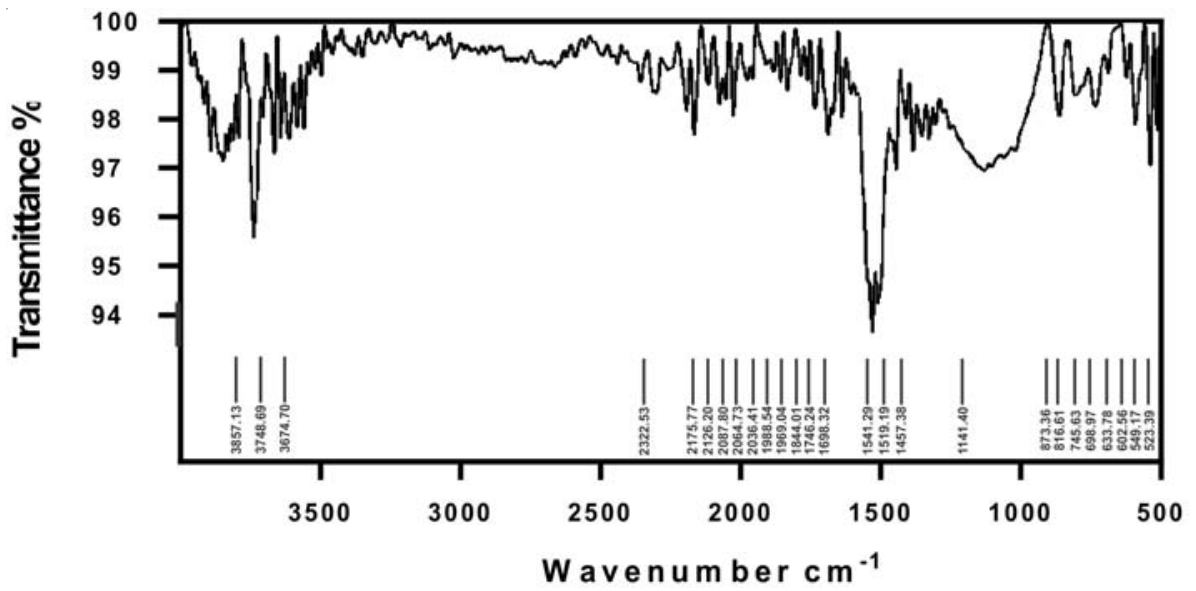

Fig. 5. FTIR spectrophotometry result for bio-sorbent before activation

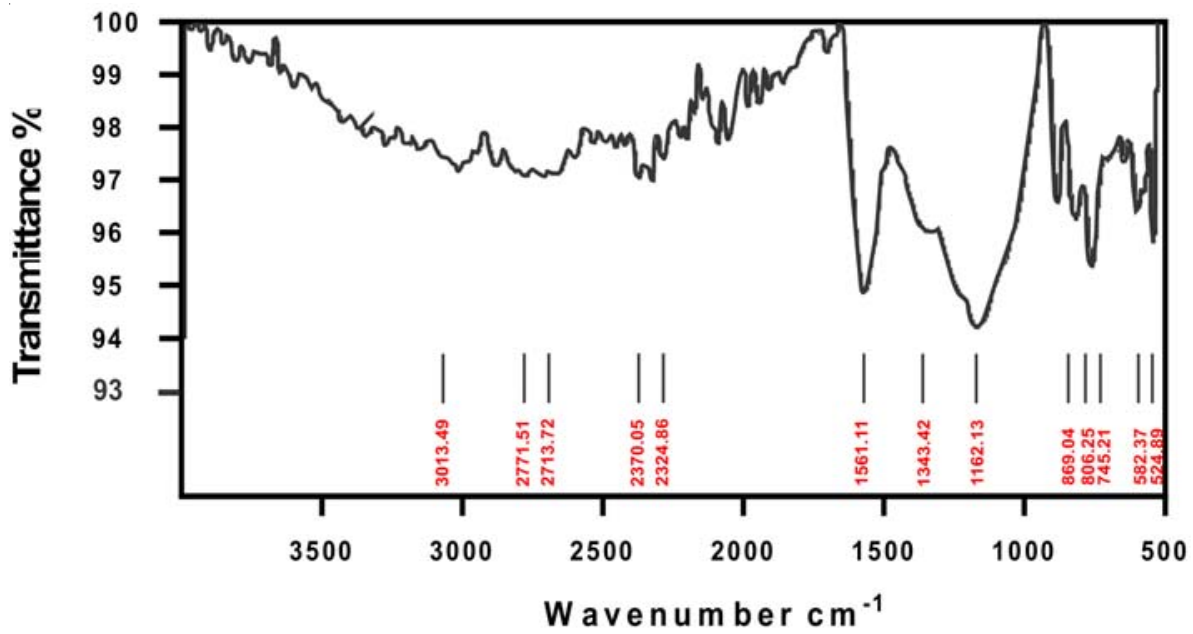

Fig. 6. FTIR spectrophotometry result for bio-sorbent after activation 


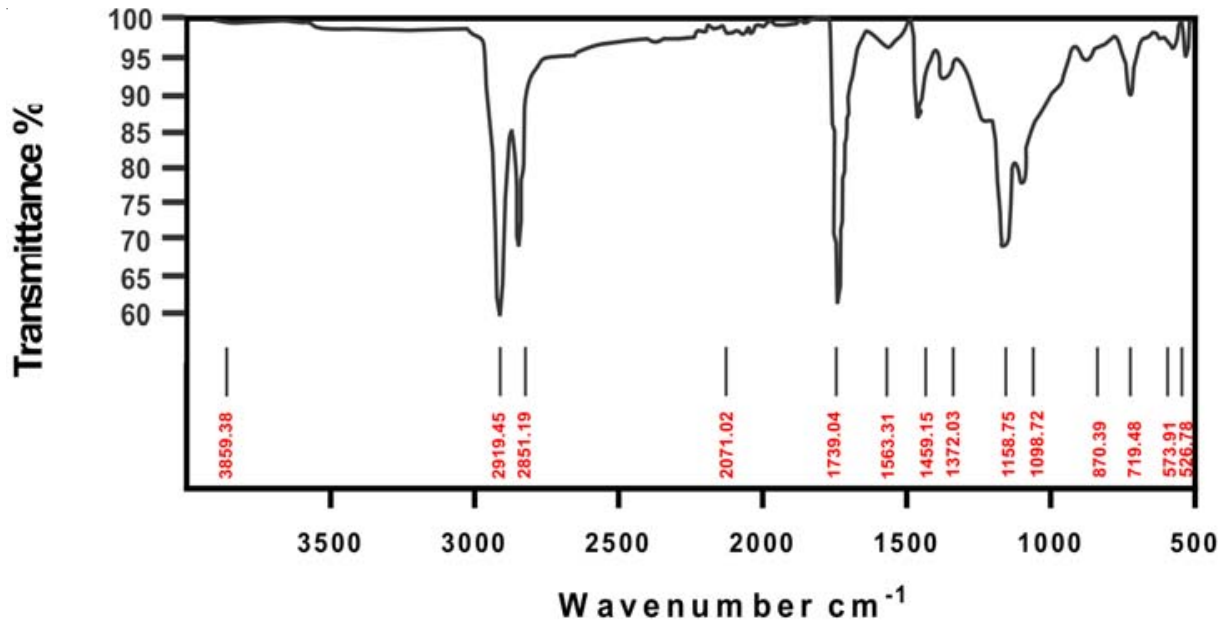

Fig. 7. FTIR spectrophotometry result for used bio-sorbent

Bio-sorbent characterization using FTIR Spectrophotometry

The characterization was conducted fix bio sorbent before and after the activation, and after used in the adsorption process. Functional groups on bio-sorbent can be inferred by comparing result on the graph with literature or IR correlation ${ }^{5}$. The graphs are in Fig. 5, 6 and 7 below:

Bio sorbent before and after activation and bio sorbent that has been used for adsorption of impurity contents on CPO subsequently characterized its functional groups by FTIR spectrophotometry. The groups present in the bio-sorbent can be summarizes by comparing the wave peaks formed with the literature, which is from the IR correlation Table ${ }^{6}$. Fig. 5 and 6 can be compared to the functional groups present in the bio-sorbent, before and after activation. The bio-sorbent before to activation contains an alkene group, an aromatic carbon ring compound, a carbon dioxide, an $-\mathrm{OH}$ group of alcohols, a nitro compound, an alkyne and an alkane. After activation, there is no more alkyne in the bio-sorbent. Activating agent $(\mathrm{KOH})$ will oxidize carbon and damage the inner surface of the carbon. Then there may be the possibility of loosening of the carbon double bond in the bio-sorbent after it is activated. The content of the hydroxyl -OH group in the rubber shell tends to interact with adsorbat ${ }^{5}$.

Alkanol or alcohol groups affect the bio sorbent, free fatty acids, peroxides, and polar organic substances. $\mathrm{KOH}$ will react with carbon so that it will form new pores and produce carbon dioxide that diffuses to the carbon surface, where the activating agent $\mathrm{KOH}$ will oxidize the carbon and damage the inner surface of the carbon so that pore will be formed and increase adsorption ${ }^{7}$. In bio-sorbents that have been contact with $\mathrm{CPO}$, there are several functional groups bound by bio-sorbents after contacting. At the wave number $2919.45 \mathrm{~cm}^{-1}$, there is a C-O group of carboxylic acid which is an indication of free fatty acid compound. In the wave number $3859.38 \mathrm{~cm}^{-1}$ there is $-\mathrm{OH}$ group which is an indication of the attached polar peroxide compound. Aldehydes are compounds that cause turbidity and rancid odor or rancid in oil. In the wave number $1739.04 \mathrm{~cm}^{-1}$, there is an ester group.The amine and nitro compounds present in the bio-sorbent, both before and after activation, and after contact with CPO, are most likely to be obtained from rubber shells from soil and crop fertilizers. The major fat or oil damage is due to oxidation and hydrolytic events, both enzymatic and no enzymatic. Damage to palm oil causes rancid or rancid odors mainly caused by aldehydes and ketones ${ }^{3}$. From the results of IR spectrophotometry, it can be concluded that the bio sorbent from the shell of the rubber fruit can adsorb the carboxylic acid content in the form of free fatty acids, peroxide compounds, and aldehydes from palm oil.

Bio-sorbent characterization using (SEM) (Scanning Electron Microscope)

Characterization of the rubber-fruit shell bio-sorbent before and after activation is done to 
determine the shape of the changes on the surface of the bio-sorbent with magnification 1000x.

The graphs are in Fig. 8 and 9 below

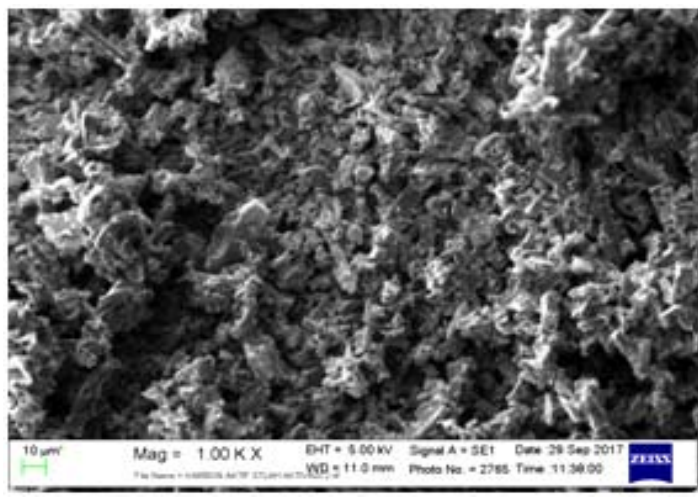

Fig. 8. Scanning Electron Microscope result for bio-sorbent before activation

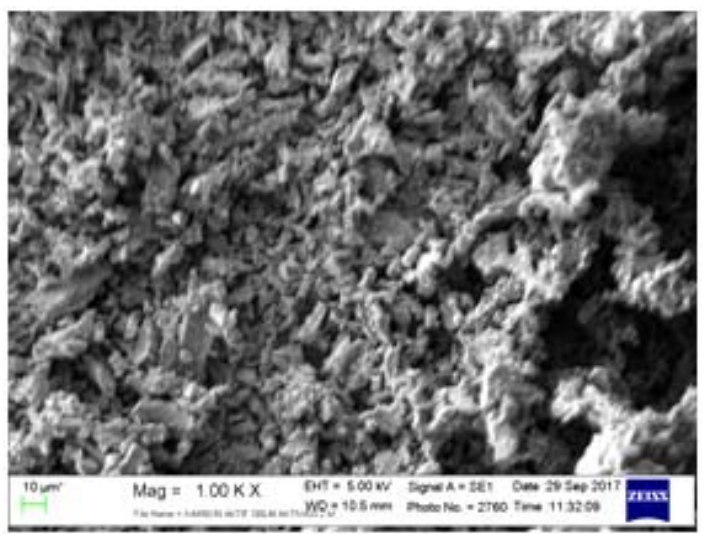

Fig. 9. Scanning Electron Microscope result for bio sorbent after activation

Figure. 8 and 9 above show the difference of pore structure of bio-sorbent shell of rubber fruit before and after activation. In the bio sorbent of the shell of the rubber fruit before activation is formed pores that are not as much as bio sorbent after activation. For bio-sorbents after the activation of $\mathrm{KOH}$, it has formed a wider pore structure and spreads throughout the bio-sorbent surface. The more pore structure on the surface of the bio sorbent the higher the ability to absorb fluid and gas. The increase in porosity is also due to the amount of impregnating agent used, the more activators used will increase pore formation on activated carbon ${ }^{9}$. The process of carbonization and activation affects the pore structure of a material. According to Novicio et al., ${ }^{10}$ the formation of a pore due to the evaporation of a flying substance contained in the raw material caused by the carbonation process. The pores formed are estimated at 6-15 A. The more pores formed on the surface of the bio sorbent, theability to adsorb the solution and gas will increase. The pores formed have a Van Der Walls style that is a force that can attract molecules resulting in adsorption events.

The carbonization process in the bio sorbent used a temperature of $600{ }^{\circ} \mathrm{C}$ and the bio sorbent activation process at a dose of $1: 5$. The temperature used causes the formation of suspected ash impurities. Ash is the result of degradation of inorganic or mineral compounds by high temperatures. The formation of ash in the bio sorbent can be seen in Fig. 9. The white image is suspected to be the ash content attached to the material. In the figure shows that the ash content in the bio sorbent before activation is lower than after activation. The formation of ash on the surface of the bio sorbent is caused by the carbonization process carried out at a temperature of $600{ }^{\circ} \mathrm{C}$. In the bio sorbent after activation, the formation of ash tends to increase the structure of the pores.

\section{Effect of Bio Sorbent Dose and Contact Time on Peroxide Number in CPO}

The initial peroxide number in CPO used was $0.0153 \mathrm{meq} / \mathrm{kg}$. Peroxide number in CPO after being contacted with bio sorbent is given in Table 1 below

\section{Table. 2: The Removal of Peroxide Number in} CPO after adsorption (\%)

\begin{tabular}{lccc}
\hline $\begin{array}{l}\text { Dose of Bio } \\
\text { sorbent (\%) }\end{array}$ & \multicolumn{3}{c}{$\begin{array}{c}\text { The Removal of Peroxide } \\
\text { Number (\%) } \\
\text { Time (minutes) }\end{array}$} \\
\hline & 30 & 40 & 50 \\
0.5 & 74.71 & 83.86 & 70.39 \\
1.0 & 48.04 & 55.75 & 65.29 \\
1.5 & 69.61 & 77.71 & 62.22 \\
\hline
\end{tabular}

From this study can be seen the decrease of peroxide number in CPO in various dose of bio-sorbent and contact time (Table. 2). Unsaturated fatty acid can form peroxide compound. Due to experiment data, the longer contact time of adsorption cannot increase the capability of adsorbent because of desorption process. Desorption is happened due to saturated surface of adsorbent. The standart of peroxide number in CPO after adsorption is zero $\mathrm{meq} / \mathrm{kg}^{7}$. Using $0.5 \%$ dose of bio sorbent with 40 minutes of contact time, the removal of peroxide number was $83,86 \%$. 


\section{CONCLUSION}

1. The iodine number of the rubber fruit shell of $913.680 \mathrm{mg} /$ gis obtained from activation at $600{ }^{\circ} \mathrm{C}$ using $6 \mathrm{~N} \mathrm{KOH}$ with bio sorbent ratio to $\mathrm{KOH}$ is $1: 5(\mathrm{~m} / \mathrm{v})$.

2. The maksimum removal of peroxide number in CPO obtained was $83.86 \%$ at a dosage of $0.5 \%$ bio sorbent and 40 minutes of contact time.

\section{REFERENCES}

1. Zakaria, Z. A,; M Surtmaw, M.; Mohammed, N.; Achmad, W. A,;Chromium (VI) Removal from Aqueous Solution by Untreated Rubber Wood Sawdust. Elsevier Science Direct., 2008.

2. Copeland, D.; Maurice, B. W.; 2005 Vegetable Oil Refining US Patent., 2005, 58, 68444.

3. K L Er, K. L.; Quality Control Laboratories in Refineries, Proceedings of Workshop on Quality in The Palm Oil Industry. 1955, 203-208.

4. Fereidoon S.; Bayley's Industrial Oil and Fat Products $6^{\text {th }}$ Ed Jhon Wiley and Sons. Inc., 2005.

5. Nilaujana, R.; Use of Plant Material as Natural Coagulants for Treatment of Wastewater Access $1^{\text {st }}$ of March 2014 from Vision review Point http:www.visionre viewpoint.com/article.asp., 2005.

6. Skoog, D. A.; Holler, F. J.; Niesman, T. A.;
Principles of Instrumental Analysis $5^{\text {th }} \mathrm{Ed}$ Orlando Harcourt Brace., 1988.

7. Thomas, B. M.;Maby, M. M.; Shaleesha; Comparative Analysis of Coast Effective Bio sorbents in the Removal of Chromium and Iron from Aqueous Solution Advanced Bio Tech Article., 2013, 12.

8. Teng, H.; Hsu, L.; Influence Of Different Chemical Reagents on the Preparation of Activated Carbon From Bituminous Coal. Fuel Processing Technology., 2000, 64, 55-166.

9. Novicio, L. P.; Hata, T.; Kajimoto, T.; Imamura, Y.; Ishihara, S.; Removal of Mercury From Aqueous Solution of Mercurc Chloride Using Wood Powder Carbonized at Hing Temperature. J. of Wood Research., 1998, 85, 48-55. 